\title{
Improving the Service Quality of Public Transit with Exclusive Bus Lanes: A Perspective from Passenger Satisfaction
}

\author{
Linghui He $\mathbb{D}^{1}{ }^{1}$ Dongyuan Yang $\mathbb{D}^{1},{ }^{1}$ and Jian Li $\mathbb{D}^{1,2}$ \\ ${ }^{1}$ Key Laboratory of Road and Traffic Engineering of the Ministry of Education, Tongji University, Shanghai 201804, China \\ ${ }^{2}$ College of Transportation Engineering, Tongji University, Shanghai 201804, China \\ Correspondence should be addressed to Jian Li; jianli@tongji.edu.cn
}

Received 8 June 2021; Revised 22 August 2021; Accepted 17 September 2021; Published 7 October 2021

Academic Editor: Arkatkar Shriniwas

Copyright (c) 2021 Linghui He et al. This is an open access article distributed under the Creative Commons Attribution License, which permits unrestricted use, distribution, and reproduction in any medium, provided the original work is properly cited.

Exclusive bus lanes have been widely regarded as an effective way to promote bus priority and improve the service quality, while they have not attracted more passengers to travel by bus in China. Also, more attention is usually paid to the infrastructure and facilities of exclusive bus lanes, but not much attention is paid to the passenger satisfaction of public transit with them. Therefore, this paper studies how to improve the service quality of public transit with exclusive bus lanes from a perspective of passenger satisfaction. A Structural Equation Model (SEM) was developed to investigate the mechanism of relationships between passenger satisfaction and the factors influencing the service quality of public transit with exclusive bus lanes. A total of 2087 respondents from Shanghai, China, participated in this study. Also, a comparison model of different groups using public transit including captive riders, choice riders, and captive by choice riders was established. Results show that passengers were dissatisfied with the current service of public transit with bus lanes, while they would prefer to take buses in the near future. In addition, travel environment, facilities, and convenience, rather than operational efficiency, had significant effects on passenger satisfaction. Through the comparison model, it was found that choice and captive by choice users might prefer public transit with bus lanes and captive users might be unable to bear the financial burden of private motorized travel. "Crowdedness in the buses on bus lanes during peak hours" especially for choice riders and "driving stability" especially for captive riders were the improvement direction for attracting more passengers to travel by bus. The results and the proposed policies of this study can benefit for the planning and operations of exclusive bus lanes in Shanghai and other similar cities around the world.

\section{Introduction}

Public transit has been considered as an effective way to reduce urban traffic congestion and pollution emissions. The Chinese government has long been committed to giving priority to the development of public transit. Among many initiatives, the construction of exclusive bus lanes is a sustainable strategy. Exclusive bus lanes in China are a part of the road which are intended to be used only by buses, and regular vehicles cannot drive on bus lanes during peak hours. Exclusive bus lanes can improve the bus speed [1], reveal significant safety benefits by reducing the quote of crashes [2], and lessen the impact of urban congestion on public transport, so as to promote bus priority and improve the service quality of public transit. Furthermore, exclusive bus lanes can help buses pass congested traffic quickly so that people commuting by car are expected to shift to commute by bus. Although a number of exclusive bus lanes have been constructed in China, they have not significantly benefitted the ridership of public transit and have not attracted much more passengers to travel by bus as expected [1]. It indicates that we do not know why the advantages of exclusive bus lanes cannot attract more people to travel by bus and what bus passengers really care about in terms of the service quality of public transit with exclusive bus lanes.

Meanwhile, during the construction of exclusive bus lanes, planners and transit operators usually pay more attention to the traditional indicators related with infrastructure construction and operation effect and not much attention to the passenger experience for bus lanes [3-5]. For 
instance, Shanghai authorities set the goal of the length of bus lanes in the related policy documents [6] without considering the service quality and passenger satisfaction of bus lanes. However, public transit users' satisfaction is strongly connected with their future behaviour and then affects the public transit market. When transit department aims to increase bus ridership through bus lanes, improvements in passenger satisfaction towards public transit with bus lanes are considered important for increasing the attractiveness of public transit [7].

Since passengers' demands for service quality of public transit with exclusive bus lanes are not clear and the passengers' feelings are not considered in the planning and construction of bus lanes, exclusive bus lanes do not play their role in attracting more people to travel by bus. Also, different types of passengers have their own evaluation standards for satisfaction and demands for the public transit system, and the user heterogeneity needs to be considered. Therefore, it is necessary to find the points where passengers are really concerned to improve the service quality of public transit with exclusive bus lanes and formulate corresponding measures and strategies especially applied to bus lanes, so as to make bus lanes play their role more effectively.

This paper studies how to improve the service quality of public transit with exclusive bus lanes from a perspective of passenger satisfaction. A passenger satisfaction survey was conducted along sixteen main exclusive bus lanes in Shanghai, China, to obtain the data. A Structural Equation Model (SEM) approach was developed to investigate the mechanism of relationships between passenger satisfaction and the factors influencing the service quality of public transit with exclusive bus lanes. Satisfaction of captive riders (users who had no car and depended on public transit), choice riders (car owners who travelled by bus), and captive by choice riders (users who chose to travel by bus but could own a car) were compared. Based on the relationships between variables, policies related to exclusive bus lanes and public transit were proposed to the government and operators.

The main focus of this study is to explore the influential factors of passenger satisfaction of public transit with exclusive bus lanes and to help improve service quality of public transit with exclusive bus lanes not only to maintain the market share but also to attract more passengers to travel by bus. The study provides three contributions. First, we try to find the factors possibly to influence the passenger satisfaction of public transit with exclusive bus lanes and use the SEM approach to investigate the mechanism of relationship between different influential factors of passenger satisfaction. Second, we consider the user heterogeneity and study the difference of passenger groups for making different strategies. Third, we provide constructive suggestions for improving the bus service quality on bus lanes.

The rest of the paper consists of the following parts: Section 2 reviews the previous literatures. In Section 3, variables and hypotheses, the Structural Equation Model methodology, and calculating method of index score for measuring variable relationships are introduced. Section 4 introduces the designed survey and the collected data. In
Section 5, the Structural Equation Model is built and the results are analysed. The discussion is given in Section 6 . Section 7 presents the conclusions and future work.

\section{Literature Review}

For a long time, researchers have focused on public transit and exclusive bus lanes. The previous studies have made many efforts for improving bus service quality considering passenger experience and feelings and better planning and construction, design, and signal control of exclusive bus lanes. Also, the user segmentation is an important research topic for policy-making in the public transit market.

2.1. Research on Exclusive Bus Lanes. Research on exclusive bus lanes focused on planning and construction from a macro perspective and traffic design and signal control from a micro perspective.

From the macro perspective, researchers mostly analysed the conditions and effectiveness of bus lanes through indicators related to public transit and clarified the implementation strategies of bus lanes. A series of methods were used to discuss the bus lane capacity [8], the construction conditions [9], the effectiveness evaluation [10, 11], and the related environment and safety issues [2, 12]. These studies contributed to answering the following questions: Under what conditions is there a need to set up a bus lane? How can we evaluate the operation effect of bus lanes? How can we calculate the capacity of bus lanes? Can bus lanes improve the traffic environment and safety?

From the micro perspective, the design of bus lanes received great attentions due to the significant impacts of bus lanes on traffic flows and signal control. The related studies and methods included the bus lane design guides [13, 14], the mathematical model formulation $[15,16]$, and the simulation and optimization tools [17]. These studies provided a lot of modelling methods to optimize the signal control strategy of bus lanes and then used one bus lane or several bus lanes in a small region for empirical analysis. These studies were very helpful to increase the bus speed on bus lanes and reduce passengers' travel time.

2.2. Research on Service Quality of Public Transit. Bus service quality considering passenger experience and feelings is also an important research topic. The variables to assess the bus service quality were related to infrastructure and operations, for example, bus operation mileage, bus speed, and waiting time at stations, as well as passenger-oriented measures such as the coverage, comfort, cleanliness, and safety [18-20]. de Oña et al. [21] illustrated that the observed variables, including frequency, punctuality, speed, proximity, fare, and information, had the greatest influence on the overall bus transit service quality of Granada, Spain. Shiftan et al. [22] explored the intrinsic mechanism that influenced public transit loyalty in Israel. They assumed that transportation mode choice involved emotional dependence gradually turning to alternative options and inserted a new latent variable to reflect passengers' hedonic value and uncovered 
how emotional dependence affected public transit loyalty. The variables related to the service quality of public transit in these studies had differences, but they generally described the aspects of operation, safety, environment, fare, comfort, and so on [23]. There are standardized ways to assess service quality of public transit [24], but there are no common ways to assess passengers' satisfaction of public transit. The factors used to account for the objective are nearly different from each other, since the relationships between service quality and passenger satisfaction are complex. Therefore, most of the variables are applicable to assess the service quality on bus lanes, but the variables in more aspects should be needed to describe passenger satisfaction with bus lanes.

These proposed variables were used to study service quality of public transit through a variety of comprehensive methods. They included using the impact score to evaluate the service quality of public transit [25] and adopting the "SERVQUAL" method to evaluate the service quality in public transport, which was originally applied in retail banking, credit card services, repair and maintenance of electrical appliances, long-distance telephone services, and title brokerage [26]. In addition, the Structural Equation Model (SEM), which has been widely used in various fields $[27,28]$, was used to account for the relationship between service quality and passenger satisfaction. Allen et al. [29] presented a full Structural Equation Multiple Indicators and Multiple Causes (SEM-MIMIC) model, which corrected for heterogeneity in the perceptions of users regarding satisfaction with the various service attributes, with the overall service, and with loyalty. Some researchers studied the bus service quality through a geographical analysis; for example, Sun et al. [30] used geographical information system tools, global positioning system data, and smart card data to evaluate bus lines; Zhang et al. [31] proposed a mixed data envelopment analysis-stochastic frontier analysis (DEASFA) model to evaluate the efficiency of an urban bus operation at different periods. Based on the previous studies, de Oña and de Oña [32] summarized the evolution of research related to the different methodological approaches for service quality evaluation in the public transport sector over the years and provided a discussion of future directions.

In summary, there was less research on passenger satisfaction of public transit with bus lanes. That is to say, the relationship between bus lanes and passenger satisfaction of public transit was less studied. A great number of researches focused on the customer satisfaction of public transport systems, but they did not focus on the variables related to bus lanes.

\subsection{Research on User Segmentation. Users in the public} transit market were not homogenous, which means they consisted of different groups in the light of various characteristics. In this context, four basic classes of variables were typically used to identify the user segmentation [33], including socioeconomic and sociodemographic variables, spatial variables, behaviour-based variables, and attitudinal variables. The most common sociodemographic categorizations for the first segmentation approach were based on age, gender, household, work status, and income [34]. The approach based on spatial variables focused on the home and work locations of residents and differentiates between urban, suburban, and rural areas [35]. Behaviour-based variables were used to define the behavioural patterns, such as the trip frequency and trip purpose. Attitudinal variables were used to explain and understand individual mobility behaviour to segment the population into meaningful groups [34].

Among all the user segmentation methods, the method based on socioeconomic and sociodemographic variables was the most feasible in policy-making. In this way, the concepts of captive riders and choice riders emerged, which were defined to segment the public transit market [36-39]. Captive riders were commonly defined as individuals who did not have a travel choice but public transit, and choice riders were those who chose to use public transit even though another mode, usually a car, was optional [36-38]. Recently, van Lierop and El-Geneidy [39] identified an additional group that they defined as "captive by choice." The captive by choice riders were individuals who were captive riders but were not limited to transit financially.

In a word, the core of improving the service quality of public transit with bus lanes depended on how passengers perceived the bus service quality and the mechanism of related factors interacting with their satisfaction. Thus, this paper adopted the Structural Equation Model (SEM) to study the passenger satisfaction of public transit with bus lanes. In order to consider the user heterogeneity, the concepts of captive, choice, and captive by choice riders were used to segment the public transit market in an empirical research in Shanghai, China. Distinguished from the previous studies, we study the feeling and experience of passengers using bus lanes and consider the factors related to bus lanes in the process of studying passenger satisfaction of public transit to help improve the service quality of public transit with bus lanes and the market share.

\section{Methodology}

3.1. Variables and Hypotheses. The selection of variables is the core of modelling the passenger satisfaction of public transit with bus lanes. The variables used to evaluate the service quality of public transport are also applicable in the evaluation of public transit with bus lanes, and variables related to bus lanes should be considered simultaneously. Referring to existing literature [22, 23], "comfort of environment and facilities," "reliability of operation and efficiency," and "convenience of bus trip" are chosen to present the service quality of public transit on bus lanes. "Emotional value of bus lanes" is also a chosen variable, because it is used to explore whether bus passengers feel positive emotion towards bus lanes and show emotional dependence gradually turning to alternative options [22]. "Satisfaction with bus lanes" and "willingness to travel by public transport" are final results before alternative options, which show the passengers' current and future attitudes towards public transit with bus lanes. Each variable is described in detail and how to measure the variables is explained as follows. 
3.1.1. Comfort of Environment and Facilities. Comfort of environment and facilities refers to a clean and tidy situation related to the bus system with bus lanes, which can bring about superior comfort experience to the entire bus travel process [40]. The variable measures the level of trip comfort for the passenger in several aspects, so the questions should explore the perceived physical comfort of bus seats, air conditioning, and crowdedness in the bus. Therefore, three items are used to measure "comfort of environment and facilities," namely, "crowdedness in the bus on bus lanes during peak hours," "clean and tidy condition in the bus," and "overall conditions of facilities at stations on bus lanes" $[18,19]$.

3.1.2. Reliability of Operation and Efficiency. Reliability of operation and efficiency and the related subvariables are key indicators in public transit services and are general in the application of the method. The service quality inside the vehicle considers the driver's behaviours and the driving stability [41], and the one outside the vehicle considers the vehicle speed, waiting time at stations [42]. These variables are often used to evaluate the service quality of public transit, and this study pays more attention to passengers' feelings about these variables on bus lanes. Moreover, safety is an important issue passenger faces when riding a bus [2] so frequency of breakdown is taken into account. Therefore, four items are used to measure "reliability of operation and efficiency," namely, "number of safety incidents," "speed of vehicles on bus lanes," "waiting time at bus stations along bus lanes," and " driving stability."

3.1.3. Convenience of Bus Trip. Convenience of bus trip is explored in two aspects: the access into the public transit system and the part within the public transit system. As regards the access into the public transit system, walking distance from origins to stations and from stations to destinations is adopted to reflect whether it is convenient for passengers. As for the part within the public transit system, the convenience of transfers is adopted to reflect whether the bus route and station settings match the passengers' travel need [23]. Therefore, in this study, two items are used to measure "convenience of bus trip," namely, "walking distance from origins to stations and from stations to destinations" and "convenience of transfers."

3.1.4. Emotional Value of Bus Lanes. Emotional value is the part of the value that passengers feel positive emotion through the provision of services, and the chosen items should describe the emotional dependence, attention, and sense of belonging of passengers [22]. Considering the public transit with bus lanes, the attitudes and inclinations of passengers to the active and passive emotions and identification of bus lanes are chosen. These variables explore the image of bus lanes in the minds of passengers. Three items from the aspects of active and passive emotions and identification of bus lanes are adopted to measure "emotional value of bus lanes," namely, "whether bus lanes can increase the number of public transport trips," "whether taking a bus is subject to other factors," and "taking bus lanes as a consideration for bus travel” [43].

3.1.5. Satisfaction of Public Transit with Bus Lanes. The satisfaction index has been widely used in various fields. Satisfaction of public transit with bus lanes means the degree that a customer believes his/her requirements to public transit with bus lanes have been met. Besides the satisfaction degree variable, we drew lessons from Shiftan et al. [22] and took account of two other variables. They are the current effect of bus lanes for public transit and the promotion of bus lanes. Therefore, three items are used to measure "satisfaction of public transit with bus lanes," namely, "overall satisfaction towards bus lanes," "whether bus lanes have improved the bus travel experience," and "how far the gap was from the ideal level of bus service."

\subsubsection{Willingness to Travel by Public Transit.} "Satisfaction of public transit with bus lanes" is the current attitude towards bus lanes, and "willingness to travel by public transport" is used to observe the attitude and tendency of bus passengers towards bus lanes in the future. Since the purpose of bus lanes is to absorb more people who are used to travel by car to use public transport while ensuring the current number of bus trips, it is suitable to discuss the willingness of passengers to travel by public transport. Two items are adopted to measure "willingness to travel by public transit," namely, "whether bus services will be preferred when the quality of bus lanes remains at the current level" and "whether bus will be preferred when you can choose another travel mode" [22, 23].

As for the relationship between variables, "comfort of environment and facilities," "reliability of operation and efficiency," and "convenience of bus trip" are three variables that affected the "emotional value of bus lanes" [22], because these variables that represented the service quality can form emotional dependence from the perspective of facilities, operations, and convenience. Then, the "emotional value of bus lanes" exerted an impact on "satisfaction with bus lanes," which in turn affected passengers' willingness to travel by public transit [23], which means emotional value gradually turns to alternative options. The hypotheses are listed as follows:

H1: passengers' satisfaction with comfort of environment and facilities of public transit with bus lanes has a positive effect on their emotional value of bus lanes.

$\mathrm{H} 2$ : passengers' satisfaction with reliability of operation and efficiency of public transit with bus lanes has a positive effect on their emotional value of bus lanes.

H3: passengers' satisfaction with convenience of bus trip along bus lanes has a positive effect on their emotional value of bus lanes.

H4: passengers' emotional value of bus lanes has a positive effect on their satisfaction of public transit with bus lanes. 
H5: passengers' satisfaction of public transit with bus lanes has a positive effect on their willingness to travel by public transit.

3.2. Structural Equation Model (SEM). As a general technique for statistical analysis, the concepts of SEM originated from the path analysis originally proposed by Wright [44], and then factors analysis was integrated into it and the concepts of SEM were put forward [45, 46]. SEM consists of the measurement model based on factor analysis and the structural model based on path analysis. Through these two models, relationship between variables can be identified, estimated, and verified. There are two categories of variables in SEM: latent variables and observed variables. Observed variables are those that can be directly measured. Latent variables corresponding to multiple observed variables are those that cannot be directly measured.

The most direct description method of SEM is the path diagram derived from path analysis and the basic framework of SEM is shown in Figure 1. Latent variables represented by circles consist of endogenous and exogenous ones. Endogenous latent variables $\eta$ represent those affected by the variables inside the model, and exogenous latent variables $\xi$ represent those influenced by the variables outside the model. Observed variables represented by rectangles consist of endogenous ones $(y)$ and exogenous ones $(x)$. The dotted line represents the measurement model, and the solid line represents the structural model. $\zeta$ is the error vector. $\beta$ represents the effect of endogenous latent variables on other endogenous latent variables, and $\gamma$ represents the effect of exogenous latent variables on endogenous latent variables. $\lambda_{x}$ and $\lambda_{y}$ are the intermediate carriers. $\delta$ is the measurement error associated with the exogenous observed variable $x$, and $\varepsilon$ is the measurement error associated with the endogenous observed variable $y$.

Generally, SEM is composed of three regression equations expressed in the three following equations:

$$
\begin{aligned}
& \eta=B \eta+\Gamma \xi+\zeta, \\
& Y=\Lambda_{y} \eta+\varepsilon, \\
& X=\Lambda_{x} \xi+\delta,
\end{aligned}
$$

where equation (1) represents the structural model. $B$ consisting of $\beta$ vectors and $\Gamma$ consisting of $\gamma$ vectors are coefficient matrices. Equations (2) and (3) represent the measurement model. Equation (2) represents the relationship between $Y$ consisting of endogenous observed variables $y$ and endogenous latent variables $\eta$, where $\Lambda_{y}$ is the aggregate of intermediate carrier $\lambda_{y}$. Equation (3) represents the relationship between $X$ consisting of exogenous observed variable $x$ and exogenous latent variable $\xi$, where $\Lambda_{x}$ is the aggregate of intermediate carrier $\lambda_{x}$.

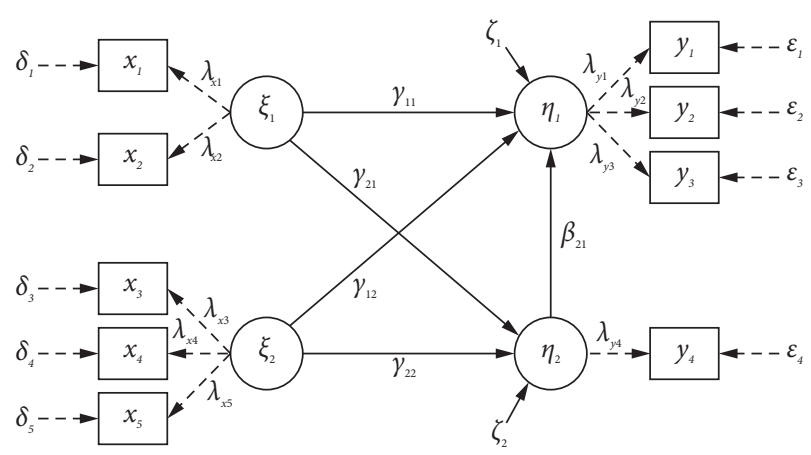

Figure 1: Structural and measurement model of SEM.

3.3. Evaluation of Model's Goodness of Fit. The goodness of fit of SEM is evaluated in two steps. First, data reliability and validity are analysed to ensure the reliability and effectiveness of the model. Second, the goodness of fit of the model is analysed to examine the model fit.

In the first step, data reliability is used to evaluate the data consistency or stability, and it is generally measured by Cronbach's alpha. In general, the data internal consistency is considered to be high, if Cronbach's alpha is greater than 0.7. If Cronbach's alpha is less than 0.4, it is considered to be less credible [22]. Data validity is generally measured by the Kaiser-Meyer-Olkin (KMO) test and the Bartlett's spherical test. Among them, value of KMO statistic is from 0 to 1 . The closer to 1 the value is, the stronger the correlation between variables is. In general, the KMO value should be greater than 0.7 to show a strong correlation between the observed variables [22]. Once the data reliability and validity are confirmed, the SEM is established and we move to the second step.

In the second step, the model parameters are estimated with appropriate parameter estimation methods first. Then, several indices, goodness of fit index (GFI), adjusted goodness of fit index (AGFI), root mean square error of approximation (RMSEA), and ratio of chi-square to degree of freedom (CMIN/DF), are used to examine the model fit [23]. The recommended cut-off values for GFI and AGFI are more than 0.900 . It can be considered good when RMSEA is less than 0.080 and less than 0.050 is better. When CMIN/DF is less than ten, it is regarded as a good value. If it is less than five, it is better. After ensuring that the goodness of fit of the model meets the standard, the model can be analysed.

3.4. Index Score for Measuring Variable Relationships. Most scholars analysed relevant conclusions based on the results of SEM, but the conclusions could be applied in general aspects. For the planners and policy-makers, they need more detailed approaches to improve the service quality of public transit with bus lanes and determine the improvement direction of bus services related to bus lanes. Consequently, an index score calculation method is 
proposed to study the relationship between variables. The American Customer Satisfaction Index (ACSI) calculation method [47] is used to calculate the index scores of variables. The equation for calculating the index score is as follows:

$$
\text { index score }=\frac{\sum_{i=1}^{k} w_{i} \overline{z_{i}}-\sum_{i=1}^{k} w_{i} \min \left\{z_{i}\right\}}{\sum_{i=1}^{k} w_{i}\left[\max \left\{z_{i}\right\}-\min \left\{z_{i}\right\}\right]} \times 100,
$$

where $w_{i}$ is the weight of the observed variable; $z_{i}$ denotes the observed variables including endogenous ones $(y)$ and exogenous ones $(x) ; \overline{z_{i}}$ is the average score of the observed variable; $\max \left\{z_{i}\right\}$ is the highest score of the observed variable; $\min \left\{z_{i}\right\}$ is the lowest score of the observed variable.

\section{Survey and Sample}

4.1. Survey. In this study, seventeen indicators as observed variables measured six latent variables. These seventeen indicators formed the main parts of designed questionnaire (Table 1). Most of the questions were set in a five-level Likert scale. We did not use the seven-level Likert scale or ten-level Likert scale because too many options made it difficult for investigators to express their true feelings. The interviewees need to answer these questions to show their attitude from "dissatisfy/disagree" to "satisfy/agree." There were two reasons why some questions cannot be measured by the fivelevel Likert scale. One was the fact that the questions introduced a single alternative, a completely opposite alternative, and an uncertain option, and there was no intermediate option between them on the basis of reality. The other was that the questions required the respondents to answer a level of the specific number, and it was not clearly distinguished after being divided into five levels. In addition to these seventeen survey questions, basic socioeconomic relevant questions were designed in the last part of the questionnaire.

The data were collected through a survey in Shanghai, China, in 2017. The investigation time was morning and evening rush hour from April 12 to April 14, 2017 (from Tuesday to Thursday), namely, 7:00 to 10:00 and 16:00 to 19: 00. During this period, bus lanes, which gave priority to buses by the replacement of original ordinary lanes in road space, were accessible for buses only and not accessible for regular vehicles like cars, trucks, and taxis. At other times, regular vehicles can drive on these special lanes. The survey issued 2087 questionnaires in the aggregate. The survey was conducted on sixteen bus lanes in the central urban area of Shanghai, taking into account the morning and evening peak hours, as shown in Figure 2. The bus lanes were selected based on different level of bus passenger flows [1]. Investigators surveyed the respondents at the bus stops along the bus lanes. If the respondents need to get on the buses when the bus came, the investigators followed the respondents to get on the bus at the same time to ensure the integrity of the whole questionnaire. To avoid the sample bias caused by only investigating the passengers that used those bus stops, when the investigators got on the bus with the former respondent and finished the survey, they continued to investigate the passengers in the bus.
Table 2 shows the distribution of sample size of each bus lane, and the maximum one-way volume of section passenger flow in peak hour [1] was considered to select the bus lanes for the analysis. At the very beginning of the survey, the investigators first introduced the background of Shanghai bus lanes to the respondents and asked them if they knew that the bus lines they were taking or they would take passed through the bus lanes. $60.6 \%$ of passengers did not know that the bus they were taking or would take would pass through the bus lanes. Then, the investigators told respondents that buses were on a bus lane to ensure we can get feedback from respondents on the experience on the bus lanes, rather than the whole travel experience. Eventually, 1860 valid questionnaires were collected with completed replies.

4.2. Data Description. According to the results of survey, the descriptive statistics are shown in Table 3. In the group of all users, $55.6 \%$ of the interviewees were female. The age of valid interviewees mostly fell in the range between 16 and $60.35 .9 \%$ of the interviewees were 25 to 34 years old, and the interviewees who were 35 to 44 years old accounted for $31.2 \%$. As for the occupation, company employees (39.6\%) and freelancers (17.6\%) accounted for most of the samples. Almost $40 \%$ of the interviewees earned 5000-10,000 RMB (equal to 726-1453 US dollars) per month, and $23.9 \%$ of the interviewees earned 10,000-20,833 RMB (equal to 1453-3026 US dollars) per month. About $60 \%$ of the interviewees travelled for 4 days or more in the past week. The respondents travelled the most for commuting. Since the survey was conducted during the operation hours of bus lanes, the results were considered effective to reflect the passenger satisfaction.

In order to consider the user heterogeneity and study the difference of passenger groups, this study segmented the survey sample based on the variables of car ownership and income. 1860 respondents were divided into choice, captive, and captive by choice groups [39, 48]:

Choice users: car owners

Captive users: people without cars and earn low income Captive by choice users: people without cars and do not earn low income

The standard of income to divide captive and captive by choice riders was $5000 \mathrm{RMB}$ per month (equal to 726 US dollars). Based on the minimum wage per month (2320 $\mathrm{RMB}$, equal to 337 US dollars) and the average monthly income (7132 RMB, equal to 1036 US dollars) of Shanghai released by human resources and social security department, a monthly income of $5000 \mathrm{RMB}$ was a relatively appropriate value.

The basic statistics of different group of passengers were analysed. There were 455 captive users (24.5\%), 395 choice users $(21.2 \%)$, and 1010 captive by choice users $(54.3 \%)$ in the survey. $61.7 \%$ of captive users were below 34 years of age, and most of the choice users' and captive by choice users' ages ranged from 25 to 44 . Choice users' annual income was higher. Captive users and captive by choice users travelled by public transit more than choice users. 
TABLE 1: Observed variables in the survey.

\begin{tabular}{|c|c|c|c|c|}
\hline Latent variable & Notation & Observed variable & Notation & Source \\
\hline $\begin{array}{l}\text { Comfort of environment } \\
\text { and facilities }\end{array}$ & ENVI & $\begin{array}{l}\text { It is crowded in the vehicles on bus lanes during } \\
\text { peak hours. } \\
\text { It is clean and tidy in the vehicles. } \\
\text { I am satisfied with the facilities at bus stations along } \\
\text { bus lanes. }\end{array}$ & $\begin{array}{l}x_{1} \\
x_{2} \\
x_{3}\end{array}$ & $\begin{array}{l}\text { Tyrinopoulos and Antoniou [18], } \\
\text { Eboli and Mazzulla [19] }\end{array}$ \\
\hline $\begin{array}{l}\text { Reliability of operation and } \\
\text { efficiency }\end{array}$ & OPER & $\begin{array}{l}\text { The number of bus accidents I encountered. } \\
\text { I am satisfied with the speed of vehicles on bus } \\
\text { lanes. } \\
\text { I am satisfied with the average waiting time at } \\
\text { stations along bus lanes. } \\
\text { I am satisfied with the driving stability. }\end{array}$ & $\begin{array}{l}x_{4} \\
x_{5} \\
x_{6} \\
x_{7}\end{array}$ & $\begin{array}{l}\text { Ma et al. [41], Gonzalez-Diaz and } \\
\text { Montoro-Sanchez [42] }\end{array}$ \\
\hline Convenience of bus trip & CONV & $\begin{array}{l}\text { I think it is convenient to transfer. } \\
\text { I am satisfied with the walking distance to stations. }\end{array}$ & $\begin{array}{l}x_{8} \\
x_{9} \\
\end{array}$ & Sun and Duan [23] \\
\hline $\begin{array}{l}\text { Emotional value of bus } \\
\text { lanes }\end{array}$ & EMOT & $\begin{array}{l}\text { Whether travelling by bus is subject to some } \\
\text { factors. } \\
\text { Bus lane will attract people who travel by car to take } \\
\text { the bus. } \\
\text { Bus lane is a consideration for bus travel. }\end{array}$ & $\begin{array}{l}y_{1} \\
y_{2} \\
y_{3}\end{array}$ & Shiftan et al. [22], Sun [43] \\
\hline $\begin{array}{l}\text { Satisfaction of public } \\
\text { transit with bus lanes }\end{array}$ & SATI & $\begin{array}{c}\text { Bus lane has improved my bus travel experience. } \\
\text { The service quality of public transit with bus lanes } \\
\text { reaches my expectation. } \\
\text { I am satisfied with bus lanes. }\end{array}$ & $\begin{array}{l}y_{4} \\
y_{5} \\
y_{6}\end{array}$ & Shiftan et al. [22] \\
\hline $\begin{array}{l}\text { Willingness to travel by } \\
\text { public transit }\end{array}$ & WILL & $\begin{array}{l}\text { I will still travel by bus even the quality of bus lane } \\
\text { retains. } \\
\text { Taking a bus will still be my first choice in the } \\
\text { future even I can choose another travel mode. }\end{array}$ & $\begin{array}{l}y_{7} \\
y_{8}\end{array}$ & $\begin{array}{c}\text { Shiftan et al. [22], Sun and Duan } \\
\text { [23] }\end{array}$ \\
\hline
\end{tabular}

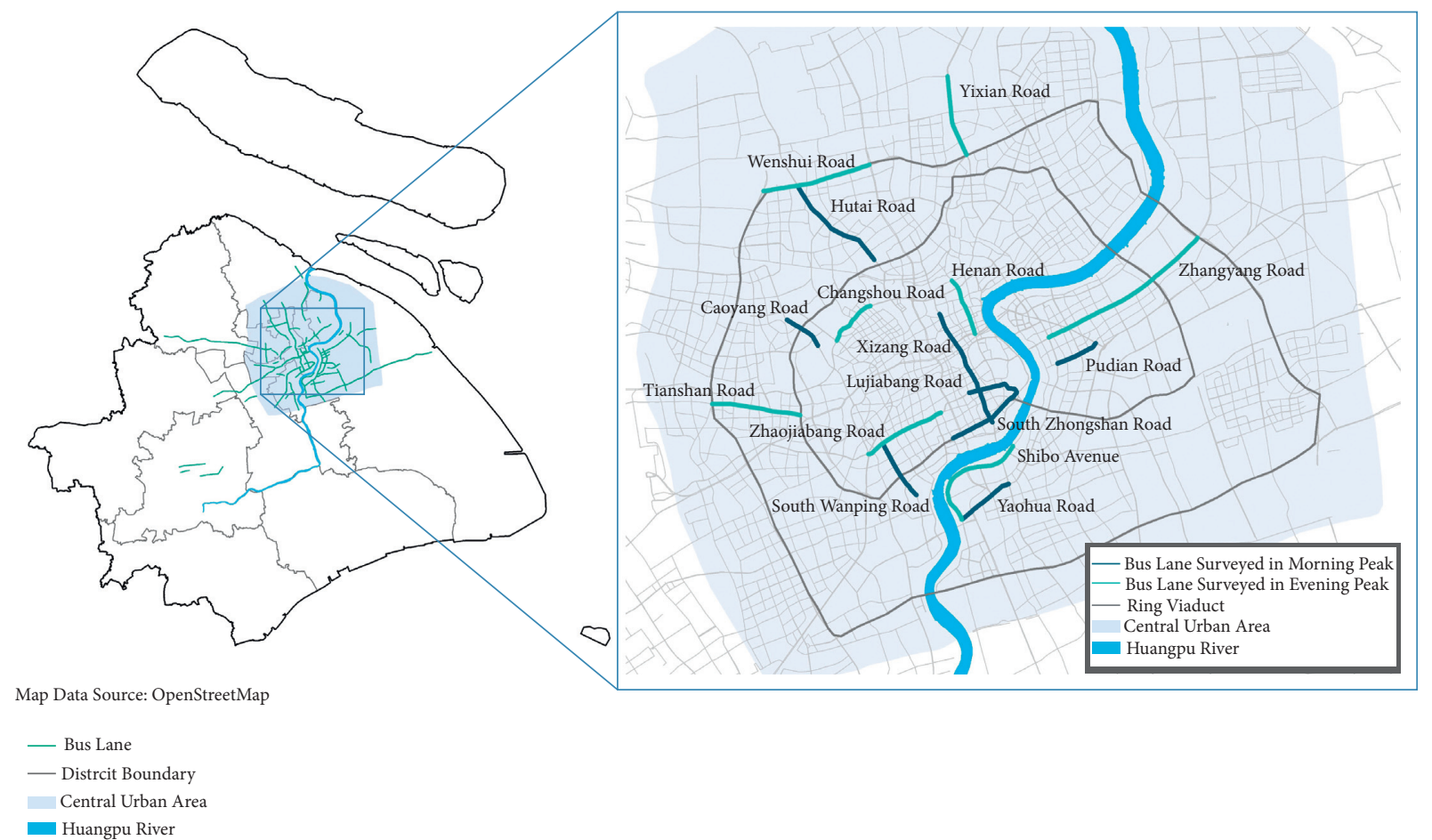

FIgURE 2: Locations and survey time of selected bus lanes.

The statistical results of observed variables are shown in Table 4. All users were not satisfied with the congestion situation in buses during peak hours (2.06), and they hardly considered bus lanes can attract people who travelled by car to take the bus (2.42). For different groups of users, choice users were the most dissatisfied with the congestion situation 
TABLe 2: Sample size of selected bus lanes.

\begin{tabular}{|c|c|c|}
\hline Bus lane & Sample size & Passenger intensity \\
\hline $\begin{array}{l}\text { Lujiabang Road } \\
\text { Zhaojiabang Road }\end{array}$ & $\begin{array}{l}200 \\
200\end{array}$ & More than 5000 persons/hour \\
\hline $\begin{array}{l}\text { Hutai Road } \\
\text { Xizang road } \\
\text { South Wanping Road } \\
\text { Yixian Road } \\
\text { Changshou Road } \\
\text { Tianshan Road } \\
\end{array}$ & $\begin{array}{l}150 \\
150 \\
150 \\
150 \\
150 \\
150 \\
\end{array}$ & More than 2000 persons/hour \\
\hline $\begin{array}{l}\text { Yaohua Road } \\
\text { Henan Road } \\
\text { Shibo Avenue } \\
\text { South Zhongshan Road }\end{array}$ & $\begin{array}{l}100 \\
100 \\
100 \\
100 \\
\end{array}$ & More than 1000 persons/hour \\
\hline $\begin{array}{l}\text { Pudian Road } \\
\text { Caoyang Road } \\
\text { Wenshui Road } \\
\text { Zhangyang Road }\end{array}$ & $\begin{array}{l}75 \\
75 \\
75 \\
75\end{array}$ & Less than 1000 persons/hour \\
\hline
\end{tabular}

TABle 3: Descriptive statistics of valid samples.

\begin{tabular}{|c|c|c|c|c|c|}
\hline & \multicolumn{4}{|c|}{ Exclusive bus lanes $N=1860(\%)$} \\
\hline & & All users (100.0) & Captive (24.5) & Choice (21.2) & Captive by choice (54.3) \\
\hline \multirow{2}{*}{ Gender } & Male & 44.4 & 45.3 & 42.3 & 44.9 \\
\hline & Female & 55.6 & 54.7 & 57.7 & 55.1 \\
\hline \multirow{5}{*}{ Age } & $16-24$ & 13.9 & 38.0 & 6.1 & 6.0 \\
\hline & $25-34$ & 35.9 & 23.7 & 41.0 & 39.3 \\
\hline & $35-44$ & 31.2 & 15.4 & 37.7 & 35.8 \\
\hline & $45-60$ & 14.7 & 16.0 & 12.7 & 14.9 \\
\hline & $>60$ & 4.4 & 6.8 & 2.5 & 4.0 \\
\hline \multirow{9}{*}{ Occupation } & Civil servant & 4.4 & 0.7 & 6.6 & 5.1 \\
\hline & Company employee & 39.6 & 12.1 & 49.1 & 48.2 \\
\hline & Freelancer & 17.6 & 18.7 & 15.4 & 18.0 \\
\hline & Student & 9.7 & 26.8 & 3.5 & 4.4 \\
\hline & Self-employee & 9.9 & 10.5 & 15.9 & 7.2 \\
\hline & Worker & 4.2 & 5.5 & 2.8 & 4.3 \\
\hline & Farmer & 2.0 & 4.2 & 0.3 & 1.7 \\
\hline & Retiree & 4.1 & 8.8 & 2.8 & 2.6 \\
\hline & Other & 8.5 & 12.7 & 3.5 & 8.5 \\
\hline \multirow{7}{*}{ Annual income (RMB) } & None & 9.6 & 34.3 & 5.6 & 0.0 \\
\hline & $<25,000$ & 3.1 & 11.0 & 1.8 & 0.0 \\
\hline & $25,000-60,000$ & 15.3 & 54.7 & 8.9 & 0.0 \\
\hline & $60,000-120,000$ & 39.6 & 0.0 & 35.4 & 59.0 \\
\hline & $120,000-250,000$ & 23.9 & 0.0 & 32.2 & 31.4 \\
\hline & $250,000-500,000$ & 6.9 & 0.0 & 11.6 & 8.1 \\
\hline & $>500,000$ & 1.8 & 0.0 & 4.6 & 1.5 \\
\hline \multirow{6}{*}{ Days travelled by bus last week } & 1 & 14.4 & 7.5 & 28.4 & 12.0 \\
\hline & 2 & 9.8 & 11.0 & 12.7 & 8.2 \\
\hline & 3 & 16.1 & 16.9 & 17.0 & 15.3 \\
\hline & 4 & 12.8 & 12.5 & 10.1 & 14.0 \\
\hline & 5 & 28.9 & 29.7 & 23.3 & 30.7 \\
\hline & $6-7$ & 18.1 & 22.4 & 8.6 & 19.8 \\
\hline \multirow{6}{*}{ Trip purpose } & For commuting & 34.7 & 25.1 & 26.8 & 42.2 \\
\hline & For school & 7.0 & 21.8 & 3.8 & 1.6 \\
\hline & For business & 14.6 & 10.8 & 15.4 & 15.9 \\
\hline & For shopping & 10.5 & 6.2 & 16.2 & 10.2 \\
\hline & For entertainment & 10.1 & 7.0 & 13.2 & 10.2 \\
\hline & Other & 23.2 & 29.2 & 24.6 & 19.9 \\
\hline \multirow{2}{*}{ Car ownership } & Yes & 21.2 & 0.0 & 100.0 & 0.0 \\
\hline & No & 78.8 & 100.0 & 0.0 & 100.0 \\
\hline
\end{tabular}


TABLE 4: Statistical results of observed variables.

\begin{tabular}{|c|c|c|c|c|c|c|c|c|c|c|c|}
\hline \multirow[t]{2}{*}{ Latent variable } & \multirow[t]{2}{*}{ Observed variable } & \multirow[t]{2}{*}{ Min } & \multirow[t]{2}{*}{ Max } & \multicolumn{2}{|c|}{ All users } & \multicolumn{2}{|c|}{ Captive } & \multicolumn{2}{|c|}{ Choice } & \multicolumn{2}{|c|}{$\begin{array}{l}\text { Captive by } \\
\text { choice }\end{array}$} \\
\hline & & & & Mean & SD & Mean & $\mathrm{SD}$ & Mean & SD & Mean & SD \\
\hline \multirow{3}{*}{ ENVI } & $x_{1}$ & 1 & 5 & 2.06 & 0.845 & 2.11 & 0.967 & 1.99 & 0.764 & 2.06 & 0.816 \\
\hline & $x_{2}$ & 1 & 5 & 3.21 & 0.739 & 3.23 & 0.769 & 3.20 & 0.717 & 3.20 & 0.734 \\
\hline & $x_{3}$ & 1 & 5 & 3.56 & 0.729 & 3.49 & 0.802 & 3.65 & 0.671 & 3.55 & 0.714 \\
\hline \multirow{4}{*}{ OPER } & $x_{4}$ & 1 & 4 & 3.34 & 0.848 & 3.35 & 0.841 & 3.52 & 0.692 & 3.26 & 0.894 \\
\hline & $x_{5}^{4}$ & 1 & 5 & 3.13 & 0.890 & 3.21 & 0.907 & 3.19 & 0.789 & 3.06 & 0.915 \\
\hline & $x_{6}$ & 1 & 5 & 3.64 & 0.930 & 3.51 & 0.986 & 3.70 & 0.861 & 3.67 & 0.926 \\
\hline & $x_{7}$ & 1 & 5 & 2.69 & 0.764 & 2.79 & 0.853 & 2.59 & 0.711 & 2.69 & 0.736 \\
\hline \multirow{2}{*}{ CONV } & $x_{8}$ & 1 & 5 & 3.26 & 0.726 & 3.26 & 0.751 & 3.26 & 0.672 & 3.25 & 0.736 \\
\hline & $x_{9}$ & 1 & 5 & 3.07 & 0.801 & 3.08 & 0.869 & 3.07 & 0.763 & 3.07 & 0.785 \\
\hline \multirow{3}{*}{ EMOT } & $y_{1}$ & 1 & 2 & 1.77 & 0.421 & 1.75 & 0.431 & 1.81 & 0.393 & 1.76 & 0.427 \\
\hline & $y_{2}$ & 1 & 5 & 2.42 & 0.779 & 2.47 & 0.860 & 2.43 & 0.745 & 2.39 & 0.753 \\
\hline & $y_{3}$ & 1 & 3 & 2.10 & 0.583 & 1.98 & 0.622 & 2.18 & 0.624 & 2.12 & 0.539 \\
\hline \multirow{3}{*}{ SATI } & $y_{4}$ & 1 & 5 & 3.11 & 0.722 & 3.00 & 0.794 & 3.20 & 0.693 & 3.11 & 0.693 \\
\hline & $y_{5}$ & 1 & 5 & 3.18 & 0.743 & 3.06 & 0.775 & 3.32 & 0.716 & 3.19 & 0.729 \\
\hline & $y_{6}$ & 1 & 5 & 2.97 & 0.700 & 3.07 & 0.674 & 2.98 & 0.681 & 2.91 & 0.713 \\
\hline \multirow{2}{*}{ WILL } & $y_{7}$ & 1 & 3 & 2.05 & 0.615 & 2.14 & 0.631 & 2.02 & 0.627 & 2.02 & 0.713 \\
\hline & $y_{8}$ & 1 & 3 & 2.32 & 0.556 & 2.31 & 0.582 & 2.34 & 0.548 & 2.32 & 0.548 \\
\hline
\end{tabular}

in the buses (1.99), and they did not consider bus lanes as one factor influencing the travel mode choice (1.98). Captive users considered the facilities at bus stations need to be improved (3.49). Among the three groups, captive by choice users remained neutral most of the time.

\section{Results}

5.1. Data Reliability and Validity. The reliability and validity of observed variables were examined first to ensure the reliability and effectiveness of the model. The results of data reliability and validity are shown in Table 5. To test the data reliability, the Cronbach's alpha value of whole data was 0.753, which was greater than 0.7. Therefore, the whole sample data were reliable. We also examined the data reliability of captive group, choice group, and captive by choice group, and the Cronbach's alpha value of each group was also greater than 0.7 . Therefore, data of all groups were also reliable according to the Cronbach's alpha and the reliability degree was close.

As regards the data validity, the statistics of KaiserMeyer-Olkin (KMO) test and the results of Bartlett's spherical test were measured. Consequently, the KMO value was 0.809 (greater than 0.7) and the significance level of Bartlett's spherical test was less than 0.001, which means the latent variables could be measured by the observed variables well. After testing different group data, it was come to the same conclusion.

5.2. Results of the General Model. The initial model of passenger satisfaction with bus lanes was established through the SEM approach shown in Figure 3. The coefficients of the model were estimated by using the whole data. The numbers attached to the solid lines represent the relationship between latent variables, and the ones attached to the dotted lines represent the relationship between latent variables and observed variables.

As shown in Figure 3, most of the indices were not in the criteria range; thus the goodness of fit of the initial model was unacceptable. The initial model needed to be adjusted. First of all, because of the strong correlation between the latent variable "comfort of environment and facilities (ENVI)" and "convenience of bus trip (CONV)" (0.934), the two variables may belong to one higher-order common latent variable. Therefore, combining the observed variables, a new latent variable was obtained. Since the new latent variable explained "comfort of environment and facilities (ENVI)" and "convenience of bus trip (CONV)," the new latent variable was defined as "service level of the travel environment (SERV)." Moreover, the latent variable "reliability of operation and efficiency (OPER)" had little effect on the "emotional value of bus lanes (EMOT)" (0.124) and other latent variables, but, in order to preserve the integrity of the model, the latent variable and its associated observed variables were retained, and it was considered to influence "willingness to travel by public transport (WILL)" directly. Finally, there may be a covariation relationship between the new latent variable (SERV) and "reliability of operation and efficiency (OPER)." To make the model more perfect, a doubleheaded arrow was set to represent the covariance relationship. In addition, the covariation relationships between the measurement errors of observed variables were adjusted based on the modification indices provided in the output results.

The results of the adjusted model and estimation results are shown in Figure 4 . The numbers in Figure 4 have the same meaning as those in Figure 3. All the relationships were significant, which means $P$ value was less than 0.001. Although some indices still had room for improvement, the goodness of fit of the model was 
TABle 5: Data reliability and validity.

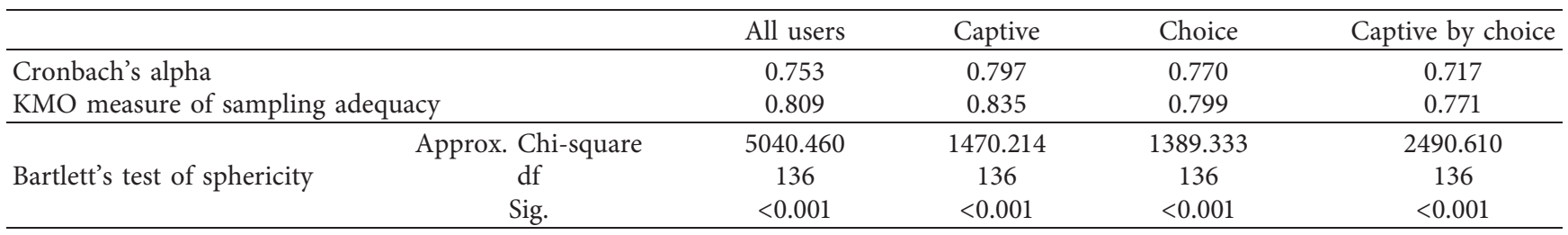

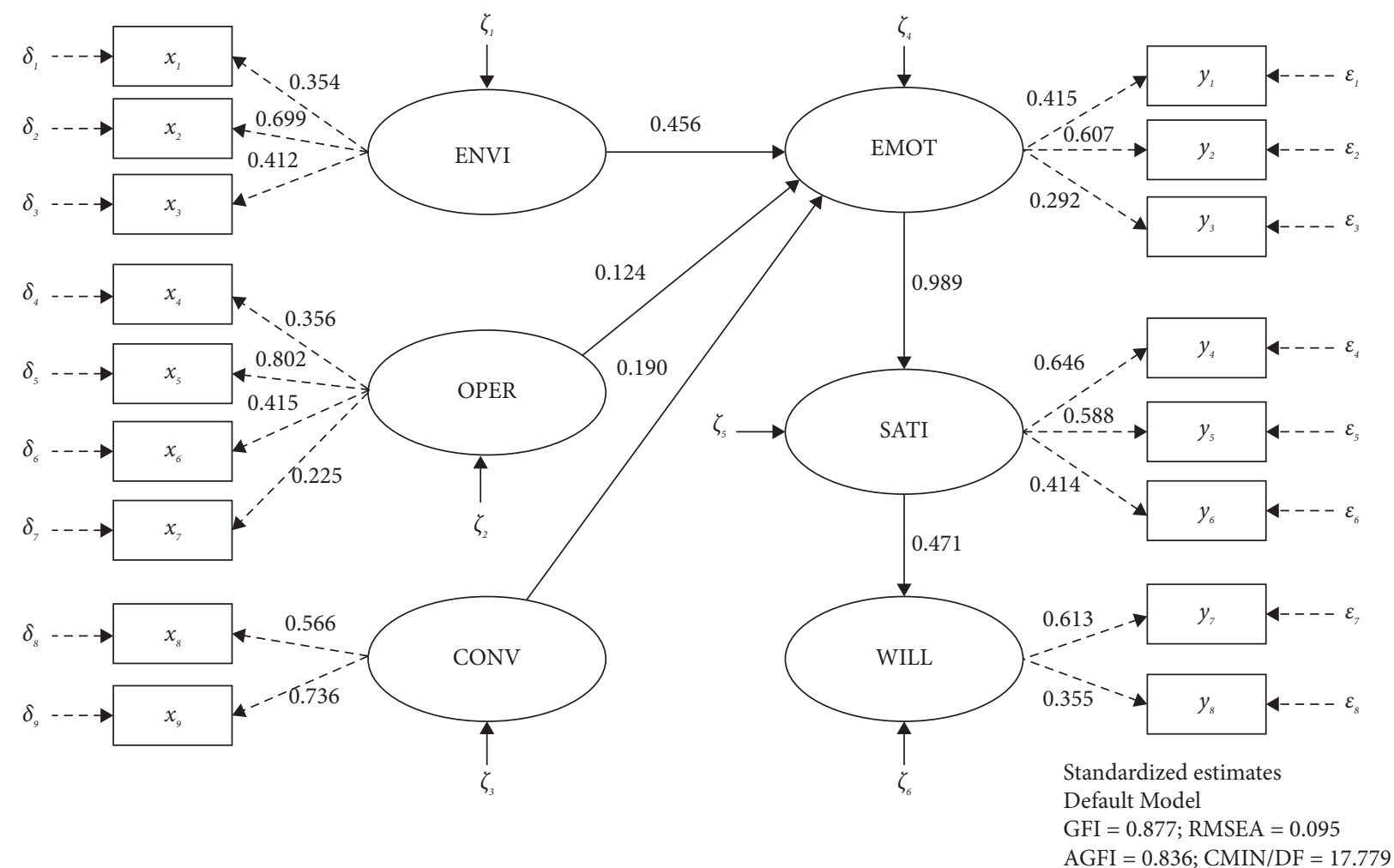

Figure 3: Results of the initial model.

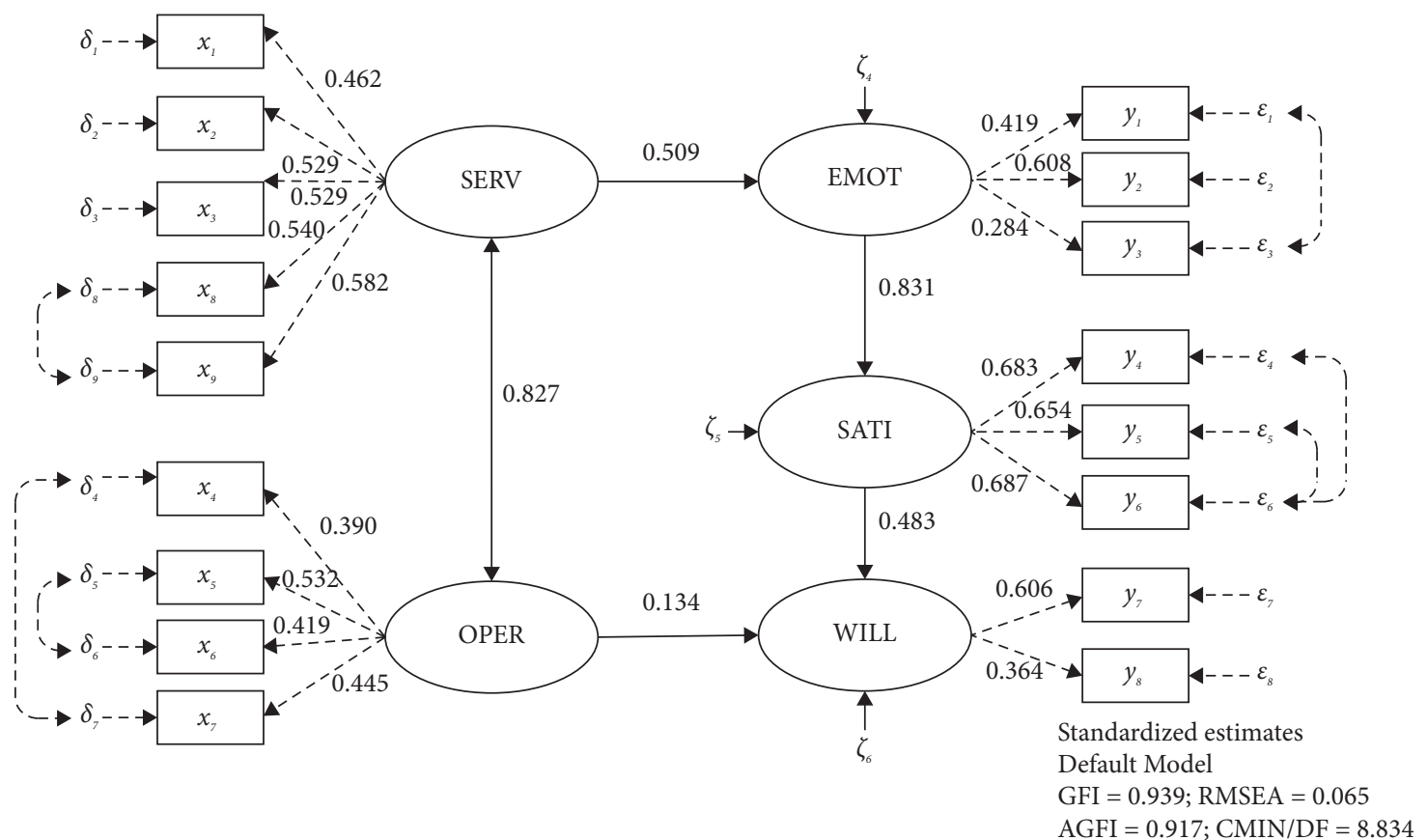

FIGURE 4: Results of the adjusted model. 
acceptable under the real condition. Then, we can analyse the relationship between variables based on the results of the adjusted model shown in Figure 4.

5.3. Relationship between Variables. The relationship between variables consisted of two parts, including the relationship between latent variables and the one between latent variables and observed variables. The relationship between variables in SEM was measured by the effects between latent variables. As shown in Table 6, the effects consisted of direct and indirect effect. The direct effect occurred between two adjacent latent variables, which could be represented by the normalized path coefficient. The indirect effect was regarded as the influence of one latent variable on another latent variable through the influence of multiple latent variables. The total effect between the latent variables was equal to the sum of direct and indirect effects.

As shown in Table 6, with one unit increase of "reliability of operation and efficiency (OPER)," passenger's willingness to travel by public transport would be promoted by 0.134 units. Therefore, the effect of "reliability of operation and efficiency (OPER)" on the "willingness to travel by public transport (WILL)" was significantly less. Emotional value of bus lane has a significantly direct effect on the satisfaction with bus lane. "Emotional value of bus lanes (EMOT)" was increased by 1 unit, which increased "satisfaction of public transit with bus lanes (SATI)" by 0.831 units. The result indicated that the passengers were more satisfied with bus lanes when they had a more positive emotional value to them. "Satisfaction of public transit with bus lanes (SATI)" had a direct impact on willingness of using public transport, and the degree of direct effect was more than that of "reliability of operation and efficiency (OPER)." "Satisfaction of public transit with bus lanes (SATI)" was increased by 1 unit, which increased "willingness to travel by public transport (WILL)" by 0.483 units.

In summary, based on the total effect of willingness to travel by public transport, it could be considered that the service level of the travel environment had a significant impact on satisfaction with bus lane and bus trip willingness through a series of latent variables.

Relationship between latent and observed variables in SEM was measured by the index score calculation method. The index score could reveal the interviewees' attitudes towards the issue and help develop strategies related to bus lanes to expand the public transit market. The index scores of latent and observed variables calculated by equation (4) are shown in Table 7.

As reported in Table 7, the service quality of bus lanes still had much potential for improvement and targeted strategies should be taken in some aspects. Specifically, "crowdedness in the bus on bus lanes during peak hours $\left(x_{1}\right)$ " and "driving stability $\left(x_{7}\right)$ " scored under 50 points. It also reflected that many passengers were sceptical that bus lane could attract people who travelled by car to take the bus. The first and most important thing was that the passenger satisfaction for bus lanes scored more than 50 points (52.13 points), and the willingness to travel by bus was 57.57 points, which was greater than the current satisfaction score for bus lanes. Since willingness reflected the intention to use the bus service in the near future, it implied that passengers had a positive attitude towards the future public transit with bus lane, despite their little dissatisfaction. It also implied that passengers might prefer public transit or simply could not bear the financial burden of private motorization.

5.4. Captive, Choice, and Captive by Choice Models. To explore whether the reason why passengers continued travelling by public transit in the near future in Shanghai was relevant with financial issues or not, the survey sample was segmented from the perspective of income and car ownership. Acknowledging that there were different groups that used transit was possible as the factors affecting satisfaction may not be consistent among all user types. As a result, it was necessary to establish comparison models to consider the user heterogeneity.

According to the analysis in Section 4, the transit users were recognized as choice, captive, and captive by choice. The structural and measurement model was established based on the model in Figure 4. First, the goodness of fit of the comparison models was evaluated, as shown in Table 8 . Almost all the estimation indexes fit the models.

Based on a comparison for different groups in Table 9, the findings for the comparison models were relatively similar to those of the general model, but there were a few differences in comparison models. The results of structural models revealed that captive users' emotional value of bus lane was influenced less by the service of the travel environment (0.399) compared to choice and captive by choice users (0.606 and 0.618). In contrast, captive users' satisfactions were influenced more by emotional value of bus lane compared to the other groups. Also, while for all groups satisfaction with operation and efficiency had greatly little effect on their willingness to travel by bus, this was much less for captive users. This might be because captive users did not have the opportunity to use an alternative mode and only travelled by bus regardless of this factor. In the measurement models, captive by choice users' preferences were closest to general groups' in the service of the travel environment. The results of captive users were lower than those of captive by choice users, while the results of choice users were higher. It is shown that the choice users had higher requirements for bus lanes. In addition, the traffic accident passengers encountered least influenced the operation and efficiency for captive users (0.324), which shows they did not care about this point. This result was different from the previous studies $[39,48]$, and it may be said that bus lanes reduced the passenger's attention to the accidents. As for the influence of subjecting to other factors on emotional value, it was the least for choice users (0.319), possibly because they have the most choices of all groups. Meanwhile, there was no significant difference between the results of measurement 
TABLE 6: Effects between latent variables.

\begin{tabular}{|c|c|c|c|c|c|c|}
\hline Latent variable & Type of effect & SERV & RELI & EMOT & SATI & WILL \\
\hline EMOT & $\begin{array}{c}\text { Direct effect } \\
\text { Indirect effect } \\
\text { Total effect }\end{array}$ & $\begin{array}{l}0.509 \\
0.509\end{array}$ & & & & \\
\hline SATI & $\begin{array}{c}\text { Direct effect } \\
\text { Indirect effect } \\
\text { Total effect }\end{array}$ & $\begin{array}{l}0.423 \\
0.423 \\
\end{array}$ & & $\begin{array}{l}0.831 \\
0.831 \\
\end{array}$ & & \\
\hline WILL & $\begin{array}{c}\text { Direct effect } \\
\text { Indirect effect } \\
\text { Total effect }\end{array}$ & $\begin{array}{l}0.204 \\
0.204\end{array}$ & $\begin{array}{l}0.134 \\
0.134\end{array}$ & $\begin{array}{l}0.401 \\
0.401\end{array}$ & $\begin{array}{l}0.483 \\
0.483\end{array}$ & \\
\hline
\end{tabular}

TABLE 7: Index scores of latent and observed variables.

\begin{tabular}{|c|c|c|c|c|c|c|c|}
\hline $\begin{array}{l}\text { Latent } \\
\text { variable }\end{array}$ & $\begin{array}{c}\text { Observed } \\
\text { variable }\end{array}$ & $\begin{array}{l}\text { Minimum } \\
\text { value }\end{array}$ & $\begin{array}{l}\text { Maximum } \\
\text { value }\end{array}$ & $\begin{array}{c}\text { Average } \\
\text { value }\end{array}$ & $\begin{array}{c}\text { Standardized } \\
\text { weight }\end{array}$ & $\begin{array}{c}\text { Index score of } \\
\text { observed variables }\end{array}$ & $\begin{array}{c}\text { Index score of latent } \\
\text { variables }\end{array}$ \\
\hline \multirow{5}{*}{ SERV } & $x_{1}$ & 1 & 5 & 2.06 & 0.462 & 26.84 & \multirow{5}{*}{51.46} \\
\hline & $x_{2}$ & 1 & 5 & 3.21 & 0.529 & 55.97 & \\
\hline & $x_{3}$ & 1 & 5 & 3.56 & 0.529 & 64.83 & \\
\hline & $x_{8}$ & 1 & 5 & 3.26 & 0.540 & 57.23 & \\
\hline & $x_{9}^{\circ}$ & 1 & 5 & 3.07 & 0.582 & 52.42 & \\
\hline \multirow{4}{*}{ OPER } & $x_{4}$ & 1 & 4 & 3.34 & 0.390 & 75.30 & \multirow{4}{*}{57.80} \\
\hline & $x_{5}$ & 1 & 5 & 3.13 & 0.532 & 51.41 & \\
\hline & $x_{6}$ & 1 & 5 & 3.64 & 0.419 & 63.72 & \\
\hline & $x_{7}$ & 1 & 5 & 2.69 & 0.445 & 40.79 & \\
\hline \multirow{3}{*}{ EMOT } & $y_{1}$ & 1 & 2 & 1.77 & 0.419 & 60.44 & \multirow{3}{*}{43.83} \\
\hline & $y_{2}$ & 1 & 5 & 2.42 & 0.608 & 27.87 & \\
\hline & $y_{3}$ & 1 & 3 & 2.10 & 0.284 & 43.17 & \\
\hline \multirow{3}{*}{ SATI } & $y_{4}$ & 1 & 5 & 3.11 & 0.683 & 52.71 & \multirow{3}{*}{52.13} \\
\hline & $y_{5}$ & 1 & 5 & 3.18 & 0.654 & 54.46 & \\
\hline & $y_{6}$ & 1 & 5 & 2.97 & 0.687 & 49.21 & \\
\hline \multirow{2}{*}{ WILL } & $y_{7}$ & 1 & 3 & 2.05 & 0.606 & 51.01 & \multirow{2}{*}{57.57} \\
\hline & $y_{8}$ & 1 & 3 & 2.32 & 0.364 & 64.12 & \\
\hline
\end{tabular}

TABLE 8: Estimation index of comparison models and recommended cut-off values.

\begin{tabular}{|c|c|c|c|c|}
\hline Index & Captive & Choice & Captive by choice & Recommended cut-off values \\
\hline GFI & 0.938 & 0.908 & 0.929 & $>0.900$ \\
\hline AGFI & 0.916 & 0.876 & 0.904 & $>0.900$ \\
\hline RMSEA & 0.053 & 0.075 & 0.067 & $<0.050$ (great),$<0.080$ (good) \\
\hline CMIN/DF & 2.282 & 3.193 & 5.508 & $<5$ (great), $<10($ good $)$ \\
\hline
\end{tabular}

models related to "satisfaction of public transit with bus lanes" and "willingness to travel by public transport" for all groups.

\section{Discussion}

The results of the general and comparison models could provide several targeted approaches to increase the service quality of public transit with bus lanes. In this section, these strategies are discussed to increase passenger satisfaction among different types of public transit users. Increasing the service quality and satisfaction of public transit with bus lanes was expected to increase the bus ridership among different groups.

As shown in Figure 5, the index score of each variable in each model was calculated. The first thing to pay attention to was the fact that choice users scored almost the same in "satisfaction of public transit with bus lanes" (54.06) and "willingness to travel by public transit" (56.56). It implied that choice users along bus lanes had a positive attitude towards the public transit with bus lanes at present and were confident in future transit services. Different from choice 
TABLE 9: Comparing results for different groups.

\begin{tabular}{|c|c|c|c|c|c|c|}
\hline & & & & Captive & Choice & Captive by choice \\
\hline \multirow{5}{*}{ Structural model } & SERV & $\leftrightarrow$ & OPER & 0.858 & 0.675 & 0.882 \\
\hline & EMOT & $\leftarrow$ & SERV & 0.399 & 0.606 & 0.618 \\
\hline & SATI & $\leftarrow$ & EMOT & 0.841 & 0.781 & 0.823 \\
\hline & WILL & $\leftarrow$ & OPER & 0.052 & 0.114 & 0.252 \\
\hline & WILL & $\leftarrow$ & SATI & 0.510 & 0.520 & 0.407 \\
\hline \multirow{17}{*}{ Measurement model } & $x_{1}$ & $\leftarrow$ & SERV & 0.446 & 0.540 & 0.444 \\
\hline & $x_{2}$ & $\leftarrow$ & SERV & 0.481 & 0.606 & 0.570 \\
\hline & $x_{3}$ & $\leftarrow$ & SERV & 0.493 & 0.619 & 0.545 \\
\hline & $x_{8}$ & $\leftarrow$ & SERV & 0.491 & 0.629 & 0.584 \\
\hline & $x_{9}$ & $\leftarrow$ & SERV & 0.537 & 0.673 & 0.603 \\
\hline & $x_{4}$ & $\leftarrow$ & OPER & 0.324 & 0.436 & 0.477 \\
\hline & $x_{5}$ & $\leftarrow$ & OPER & 0.510 & 0.523 & 0.577 \\
\hline & $x_{6}$ & $\leftarrow$ & OPER & 0.429 & 0.327 & 0.492 \\
\hline & $x_{7}$ & $\leftarrow$ & OPER & 0.403 & 0.439 & 0.498 \\
\hline & $y_{1}$ & $\leftarrow$ & EMOT & 0.431 & 0.319 & 0.464 \\
\hline & $y_{2}$ & $\leftarrow$ & EMOT & 0.615 & 0.722 & 0.540 \\
\hline & $y_{3}$ & $\leftarrow$ & EMOT & 0.275 & 0.224 & 0.356 \\
\hline & $y_{4}$ & $\leftarrow$ & SATI & 0.655 & 0.707 & 0.706 \\
\hline & $y_{5}$ & $\leftarrow$ & SATI & 0.646 & 0.684 & 0.638 \\
\hline & $y_{6}$ & $\leftarrow$ & SATI & 0.627 & 0.735 & 0.778 \\
\hline & $y_{7}$ & $\leftarrow$ & WILL & 0.640 & 0.664 & 0.559 \\
\hline & $y_{8}$ & $\leftarrow$ & WILL & 0.302 & 0.354 & 0.484 \\
\hline
\end{tabular}

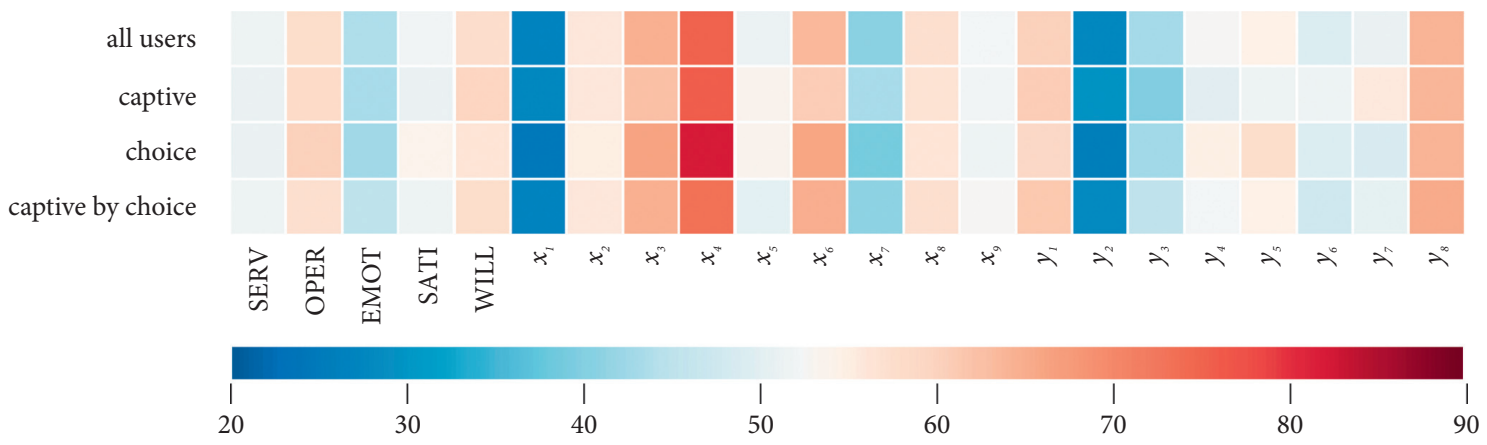

FIGURE 5: Index scores of the general and comparison models.

users, captive and captive by choice users were dissatisfied with the current situation. Therefore, it could be proved that choice and captive by choice users might prefer public transit with bus lanes and captive users might be unable to bear the financial burden of private motorized travel to choose public transit.

Another important finding was that most passengers, especially choice users, were sceptical that bus lane could attract people who travelled by car to take the bus $\left(y_{2}\right)$. Thus, it was difficult to increase user satisfaction by simply building bus lanes without improving the service quality of public transit. The results also showed that what bus passengers most wanted to improve were "crowdedness in the bus on bus lanes during peak hours $\left(x_{1}\right)$ " and "driving stability $\left(x_{7}\right)$." This result could be achieved from all groups. The results were consistent with previous studies on the whole bus system in other cities in China [23, 43]. Then, we compared our results with the research in [49] on Shanghai public transport system, including public transit without exclusive bus lanes. It is found that (1) service quality had a significant effect on satisfaction and (2) people were dissatisfied with the crowdedness in the bus. However, compared with other variables in the service quality, the dissatisfaction with the crowdedness in the bus in the whole bus system was less than that for the public transit with bus lanes. It indicated that people had high requirements for exclusive bus lanes to reduce the crowdedness in the bus.

To maintain or even improve the public transit market share, it was extremely necessary to focus on the demands of different groups of transit users. Several targeted approaches could be proposed to the transport departments and transit operators for reference. For "crowdedness in the bus on bus lanes during peak hours $\left(x_{1}\right)$," the service could be improved by optimizing the frequency of the routes passing through the bus lanes during peak hours and the setting plan of bus stations and routes along bus lanes. For "driving stability $\left(x_{7}\right)$," the service could be improved by strengthening driving training not only to improve the drivers' driving skills but also to make drivers change the driving habits 
along bus lanes. It indicated that it was important to distinguish between the driving behaviours of bus lanes and nonbus lanes. This could create smoother driving conditions through bus lanes.

These results demonstrated that it is effective to improve the passenger satisfaction of different groups through adopting the policy suggestions which focused on the specific aspects of bus lanes. In addition, improvement strategies targeted at choice and captive by choice users were important. It could not only benefit these groups and retain these users but also improve the experience of travelling by bus for users who had no opportunity to switch the travel mode. In other words, the policies targeted at specific groups could motivate other ridership as well.

\section{Conclusions and Future Work}

This paper investigated how to improve the service quality of public transit with exclusive bus lanes in Shanghai, China, from a perspective of passenger satisfaction. Based on SEM and calculation of index score, the factors related to satisfaction of public transit with bus lanes and willingness to travel by public transit were identified. Meanwhile, the effect of heterogeneity among users on the performance of the model was investigated. The findings based on model results were as follows.

On one hand, passengers who took buses along exclusive bus lanes in Shanghai were dissatisfied with the current bus service, but they would still continue to choose buses for travel in the future. Among the whole passengers, choice users along bus lanes had a positive attitude towards the public transit with bus lanes at present and were confident in future transit services. Choice and captive by choice users might prefer public transit with bus lanes and captive users might be unable to bear the financial burden of private motorized travel and choose public transit.

On the other hand, travel environment, facilities, and convenience were found to be the key influential factors for travel willingness of passengers in Shanghai. These results were confirmed by a number of studies [22, 23]. However, operational efficiency, for example, bus speed and waiting time at the station, was not significant to passengers' perceptions towards bus service quality. This was quite different from a previous study [22].

The proposed model in this paper could benefit the understanding of passenger satisfaction of public transit with exclusive bus lanes. Since "crowdedness in the bus on bus lanes during peak hours" especially for choice users and "driving stability" especially for captive users were two key influential factors, transport departments and transit operators could consider these improvement strategies, for example, optimizing the frequency of the routes passing through the bus lanes during peak hours and strengthening driving training.

However, there were certain limitations in the current analysis and future works can be intended. The relevant investigations can be made before and after the exclusive bus lanes are constructed, respectively, not only to evaluate the effect of bus lanes more accurately but also to minimize the influence of other factors on the research. In addition, passengers were identified just by socioeconomic attributes and their behavioural characteristics were not considered. There might be risks to adopt the inappropriate policy suggestions of bus service. Therefore, groups with different socioeconomic attributes, behavioural characteristics, and attitudinal preference should be taken into consideration synthetically. For instance, temporal and spatial travel characteristics of passengers can be further studied. Therefore, the specific improvement directions of bus lanes can be confirmed, and specific bus lanes can be targeted where strategies should be applied to.

\section{Data Availability}

The data used to support the findings of this study are included within the article.

\section{Conflicts of Interest}

The authors declare that there are no conflicts of interest regarding the publication of this paper.

\section{Acknowledgments}

This work was supported by the National Key R\&D Program of China (Grant no. 2018YFB1601600).

\section{References}

[1] H. Jiang, B. Chen, and M. Liu, "Challenges and strategies for exclusive bus lane in Shanghai," Urban Transport of China, vol. 14, pp. 48-53, 2016.

[2] K. C. K. Goh, G. Currie, M. Sarvi, and D. Logan, "Bus accident analysis of routes with/without bus priority," Accident Analysis and Prevention, vol. 65, pp. 18-27, 2014.

[3] D. Ku, S. Na, J. Kim, and S. Lee, "Interpretations of DownsThomson paradox with median bus lane operations," Research in Transportation Economics, vol. 83, Article ID 100909, 2020.

[4] M. Yildirimoglu, A. Petit, N. Geroliminis, and Y. Ouyang, "Bus service design under demand diversion and dynamic roadway congestion based on aggregated network models," in Proceedings of the 95th Annual Meeting of the Transportation Research Board, Washington, DC, USA, January 2016.

[5] J. Zhao and X. Zhou, "Improving the operational efficiency of buses with dynamic use of exclusive bus lane at isolated intersections," IEEE Transactions on Intelligent Transportation Systems, vol. 20, no. 2, pp. 642-653, 2019.

[6] Shanghai People's Publishing House, Shanghai Transportation Development White Paper, Shanghai Municipal People’s Government, Shanghai, China, 2014.

[7] M. Dixon, K. Freeman, and N. Toman, "Stop trying to delight your customers," Harvard Business Review, vol. 88, no. 7/8, pp. 116-122, 2010.

[8] H. S. Levinson and K. R. Jacques, "Bus lane capacity revisited," Transportation Research Record: Journal of the Transportation Research Board, vol. 1618, no. 1, pp. 189-199, 1998.

[9] B. Cesme, R. Roisman, R. Burns et al., "Strategies and barriers in effective bus lane implementation and management: best practices for use in the greater Washington, D.C. region," Transportation Research Record: Journal of the Transportation Research Board, vol. 2672, no. 8, pp. 29-40, 2018. 
[10] S. Kunihiro, C. Abhayantha, and H. Kubota, "Effectiveness of bus priority lane as countermeasure for congestion," Transportation Research Record: Journal of the Transportation Research Board, vol. 2034, pp. 103-111, 2007.

[11] Y. Bai and X. Kun, "Discussion about evaluation method of traffic efficiency adaptability of bus lane," in Proceedings of the 2009 Second International Conference on Intelligent Computation Technology and Automation, vol. 3, pp. 566-570, Zhangjiajie, China, October 2009.

[12] N. Duduta, C. Adriazola-Steil, D. Hidalgo, L. A. Lindau, and P. M. Dos Santos, "The relationship between safety, capacity, and operating speed on bus rapid transit," in Proceedings of the 13th World Conference on Transport Research, Rio de Janeiro, Brazil, July 2013.

[13] J. S. Safran, E. B. Beaton, and R. Thompson, "Factors contributing to bus lane obstruction and usage in New York city," Transportation Research Record: Journal of the Transportation Research Board, vol. 2418, no. 1, pp. 58-65, 2014.

[14] A. Petit, M. Yildirimoglu, N. Geroliminis, and Y. Ouyang, "Dedicated bus lane network design under demand diversion and dynamic traffic congestion: an aggregated network and continuous approximation model approach," Transportation Research Part C: Emerging Technologies, vol. 128, Article ID 103187, 2021.

[15] S. I. Guler and M. Menendez, "Analytical formulation and empirical evaluation of pre-signals for bus priority," Transportation Research Part B: Methodological, vol. 64, pp. 41-53, 2014.

[16] S. I. Guler, V. V. Gayah, and M. Menendez, "Bus priority at signalized intersections with single-lane approaches: a novel pre-signal strategy," Transportation Research Part C: Emerging Technologies, vol. 63, pp. 51-70, 2016.

[17] L. Truong, M. Sarvi, and G. Currie, "Do multiple combinations of bus lane sections create a multiplier effect?: a microsimulation approach," in Proceedings of the 94th Annual Meeting of the Transportation Research Board, Washington, DC, USA, January 2015.

[18] Y. Tyrinopoulos and C. Antoniou, "Public transit user satisfaction: variability and policy implications," Transport Policy, vol. 15, no. 4, pp. 260-272, 2008.

[19] L. Eboli and G. Mazzulla, "Service quality attributes affecting customer satisfaction for bus transit," Journal of Public Transportation, vol. 10, no. 3, pp. 21-34, 2007.

[20] H. Iseki and B. D. Taylor, "Style versus service? an analysis of user perceptions of transit stops and stations in Los Angeles," in Proceedings of the 87th Annual Meeting of the Transportation Research Board, Washington, DC, USA, January 2008.

[21] J. de Oña, R. de Oña, L. Eboli, and G. Mazzulla, "Perceived service quality in bus transit service: a structural equation approach," Transport Policy, vol. 29, pp. 219-226, 2013.

[22] Y. Shiftan, Y. Barlach, and D. Shefer, "Measuring passenger loyalty to public transport modes," Journal of Public Transportation, vol. 18, no. 1, pp. 1-16, 2015.

[23] S. Sun and Z. Duan, "Modeling passengers' loyalty to public transit in a two-dimensional framework: a case study in Xiamen, China," Transportation Research Part A: Policy and Practice, vol. 124, pp. 295-309, 2019.

[24] European Standard, Transportation-Logistics and ServicesPublic Passenger Transport-Service Quality Definition, Targeting and Measurement, EN 13816, European Committee for Standardisation, London, UK, 2002.

[25] G. A. Alçura, S. Ş. Kuşakc1, G. G. Şimşek, M. Gürsoy, and S. C. Tanriverdi, "Impact score technique for analyzing the service quality of a high-speed rail system," Transportation Research Record: Journal of the Transportation Research Board, vol. 2541, no. 1, pp. 64-72, 2016.

[26] R. Ladhari, "A review of twenty years of SERVQUAL research," International Journal of Quality and Service Sciences, vol. 1, no. 2, pp. 172-198, 2009.

[27] H. T. Reis and J. Stiller, "Publication trends in JPSP: a threedecade review," Personality and Social Psychology Bulletin, vol. 18, no. 4, pp. 465-472, 1992.

[28] M. D. Baer, L. van Der Werff, J. A. Colquitt, J. B. Rodell, K. P. Zipay, and F. Buckley, "Trusting the "Look and Feel": situational normality, situational aesthetics, and the perceived trustworthiness of organizations," Academy of Management Journal, vol. 61, no. 5, pp. 1718-1740, 2018.

[29] J. Allen, L. Eboli, G. Mazzulla, and J. d. D. Ortúzar, "Effect of critical incidents on public transport satisfaction and loyalty: an ordinal probit SEM-MIMIC approach," Transportation, vol. 47, no. 2, pp. 827-863, 2020.

[30] D. Sun, S. Chen, C. Zhang, and S. Shen, "A bus route evaluation model based on GIS and super-efficient data envelopment analysis," Transportation Planning and Technology, vol. 39, no. 4, pp. 407-423, 2016.

[31] K. Zhang, Y. Xu, and D. Sun, "A mixed frontier model for urban bus performance evaluation," Proceedings of the Institution of Civil Engineers - Transport, vol. 171, no. 2, pp. 65-74, 2018.

[32] J. de Oña and R. de Oña, "Quality of service in public transport based on customer satisfaction surveys: a review and assessment of methodological approaches," Transportation Science, vol. 49, no. 3, pp. 605-622, 2014.

[33] K. Markvica, A. Millonig, N. Haufe, and M. Leodolter, "Promoting active mobility behavior by addressing information target groups: the case of Austria," Journal of Transport Geography, vol. 83, Article ID 102664, 2020.

[34] S. Haustein and M. Hunecke, "Identifying target groups for environmentally sustainable transport: assessment of different segmentation approaches," Current Opinion in Environmental Sustainability, vol. 5, no. 2, pp. 197-204, 2013.

[35] K. J. Krizek and P. Waddell, "Analysis of lifestyle choices: neighborhood type, travel patterns, and activity participation," Transportation Research Record: Journal of the Transportation Research Board, vol. 1807, no. 1, pp. 119-128, 2002.

[36] E. A. Beimborn, M. J. Greenwald, and X. Jin, "Accessibility, connectivity, and captivity: impacts on transit choice," Transportation Research Record: Journal of the Transportation Research Board, vol. 1835, no. 1, pp. 1-9, 2003.

[37] K. Krizek and A. El-Geneidy, "Segmenting preferences and habits of transit users and non-users," Journal of Public Transportation, vol. 10, no. 3, pp. 71-94, 2007.

[38] C. Jacques, K. Manaugh, and A. M. El-Geneidy, "Rescuing the captive [mode] user: an alternative approach to transport market segmentation," Transportation, vol. 40, no. 3, pp. 625-645, 2013.

[39] D. van Lierop and A. El-Geneidy, "Getting committed: a new perspective on public transit market segmentation from two Canadian cities," in Proceedings of the 94th Annual Meeting of the Transportation Research Board, Washington, DC, USA, January 2015.

[40] S. Jomnonkwao and V. Ratanavaraha, "Measurement modelling of the perceived service quality of a sightseeing bus service: an application of hierarchical confirmatory factor analysis," Transport Policy, vol. 45, pp. 240-252, 2015.

[41] M. Ma, X. Yan, H. Huang, and M. Abdel-Aty, "Safety of public transportation occupational drivers: risk perception, attitudes, 
and driving behavior," Transportation Research Record: Journal of the Transportation Research Board, vol. 2145, no. 1, pp. 72-79, 2010.

[42] M. González-Díaz and Á. Montoro-Sánchez, "Some lessons from incentive theory: promoting quality in bus transport," Transport Policy, vol. 18, no. 2, pp. 299-306, 2011.

[43] S. C. Sun, "Public transit loyalty modeling considering the effect of passengers' emotional value: a case study in Xiamen, China," Journal of Advanced Transportation, vol. 2018, Article ID 4682591, 2018.

[44] S. Wright, "The method of path coefficients," The Annals of Mathematical Statistics, vol. 5, no. 3, pp. 161-215, 1934.

[45] K. G. Jöreskog, Analysis of Covariance Structures, Academic Press, New York, NY, USA, 1973.

[46] D. E. Wiley, The Identification Problem for Structural Equation Models with Unmeasured Variables, Academic Press, New York, NY, USA, 1973.

[47] C. Fornell, M. D. Johnson, E. W. Anderson, J. Cha, and B. E. Bryant, "The American customer satisfaction index: nature, purpose, and findings," Journal of Marketing, vol. 60, no. 4, pp. 7-18, 1996.

[48] D. van Lierop and A. El-Geneidy, "Enjoying loyalty: the relationship between service quality, customer satisfaction, and behavioral intentions in public transit," Research in Transportation Economics, vol. 59, pp. 50-59, 2016.

[49] H. Wang and D. Zhu, "Factors that impact bus transport satisfaction in Shanghai, China," Proceedings of the Institution of Civil Engineers-Transport, vol. 167, no. 3, pp. 185-193, 2014. 